\title{
Low lymphocyte count in underweight Japanese women
}

\author{
Tomoko Nishida $\cdot$ Hisataka Sakakibara
}

Received: 15 June 2008/Accepted: 13 August 2008/Published online: 19 September 2008

(c) The Japanese Society for Hygiene 2008

\begin{abstract}
Objective Young women being underweight is a public health problem in Japan. The aim of this study was to investigate this problem by measuring lymphocyte count as an indicator of nutritional status.

Methods The subjects were 114 women aged 20-39 who participated in an annual health checkup for residents in a city in Aichi, Japan. Data from a questionnaire, physical examination, and blood tests were analyzed in relation to women who were severely underweight [body mass index $\left.(\mathrm{BMI}) \leq 17.5 \mathrm{~kg} / \mathrm{m}^{2}\right]$, slightly underweight $(17.5<\mathrm{BMI}$ $\left.<18.5 \mathrm{~kg} / \mathrm{m}^{2}\right)$, of normal weight $\left(18.5 \leq \mathrm{BMI}<25 \mathrm{~kg} / \mathrm{m}^{2}\right)$, and obese (BMI $\left.\geq 25 \mathrm{~kg} / \mathrm{m}^{2}\right)$.

Results Lymphocyte count tended to be lower with a decrease in BMI. The prevalence of low lymphocyte count of $<1,500 / \mathrm{mm}^{3}$ increased in underweight women. In women who had restricted food intake for weight loss, leukocyte count, and total serum protein, and lymphocyte count were lower. A multivariate logistic regression analysis showed the association of low lymphocyte count to being severely underweight [odds ratio (OR): 1.95; $95 \%$ confidence interval (CI): 1.07-3.56] and to restricted food intake for weight loss (OR: 3.73; 95\% CI: 0.91-15.30).

Conclusion This study suggests that being severely underweight and on restricted food intake for weight loss in adult women can be risk factors for low lymphocyte count, an indicator of malnutrition. It is important for young women to maintain BMI $>17.5 \mathrm{~kg} / \mathrm{m}^{2}$ and not to restrict
\end{abstract}

T. Nishida $\cdot$ H. Sakakibara $(\square)$

Department of Nursing,

Nagoya University Graduate School of Medicine,

1-1-20, Daiko-minami, Higashi-ku,

Nagoya 461-8673, Japan

e-mail:sbara@met.nagoya-u.ac.jp food intake when of normal weight or underweight in order to prevent malnutrition.

Keywords Underweight - Diet · Lymphocyte · Malnutrition · Women

\section{Introduction}

Young women who are underweight is a public health problem in Japan. Young women often have a desire to lose weight and be thin $[1,2]$. In women, being underweight can be a risk for low bone mineral density (BMD), anemia, and amenorrhea [3-6]. Malnutrition is one of the important health problems for underweight people. In particular, protein nutrition, serum albumin, and lymphocyte count tend to be reduced [7]. Hence, lymphocyte count and albumin levels are used as indicators of nutritional status or protein malnutrition $[8,9]$. A low lymphocyte count of $<1,500 / \mathrm{mm}^{3}$ is considered as malnutrition $[8,10]$. As for the relationship between being underweight and leukocyte count, only a few studies have reported a decline in leukocyte and lymphocyte count in patients with anorexia nervosa who were severely thin [3, 11]. However, there are few studies on lymphocyte count among underweight women, who have not suffered from anorexia nervosa. The aim of this study was to investigate the health problems of young Japanese women by measuring the lymphocyte count as an indicator of nutritional status.

\section{Methods}

A cross-sectional study was conducted on population-based samples. The subjects were women aged 20-39 who participated in an annual health checkup for residents 
conducted 2-9 November 2005 in a city in Aichi, Japan. A total of 195 women underwent the health checkup. Among them, 180 (response rate $92.3 \%$ ) consented to participate in this study, which was approved by the ethics committee of the Nagoya University School of Medicine.

The examinations, including blood tests, were all conducted in the morning from 9 to 12 o'clock. Body mass index (BMI) $\left(\mathrm{kg} / \mathrm{m}^{2}\right)$ was calculated as weight in kilograms divided by the square of the height in meters. Blood samples were measured at the laboratory in the Handa Medical Health Care Center (Handa City, Aichi, Japan). Blood counts of leukocytes and lymphocytes were done by an automatic cell counter (Sysmex SE-9000). Differential leukocyte count was obtained microscopically. Serum concentrations of total protein were measured by a clinical autoanalyzer (HITACHI 7700). A self-report questionnaire was conducted on clinical history and lifestyle, included smoking (Never, Former, Current), drinking alcohol (on the basis of frequency: 4 days or more a week, 1-3 days a week, Occasionally, None), and restricted food intake for weight loss. Menstrual cycle was determined by Regular, Sometimes irregular, Irregular, or Amenorrhea. Restricted food intake for weight loss was determined by Not restricting food intake, Wish to restrict, but not actually, Restricting. With respect to restricted food intake, subjects were categorized into the restricting or nonrestricting group.

Subjects with amenorrhea, because of the possibility of pregnancy; current smokers; alcohol drinkers of 1 day or more a week; and persons with a cold or arthritis or rheumatism; were excluded from the analysis because leukocyte count is affected by these items [12-15]. One other subject with a leukocyte count of $13,600 / \mathrm{mm}^{3}$ was excluded because of possible infection or inflammation. There were no persons having lifestyle-related diseases such as diabetes or hyperlipidemia.

As a result, there remained 114 participants [mean \pm standard deviation (SD): $33.3 \pm 3.8$ years] for analysis. In those women, BMIs were $20.1 \pm 2.2 \mathrm{~kg} / \mathrm{m}^{2}$ in their $20 \mathrm{~s}$ and $20.7 \pm 3.0 \mathrm{~kg} / \mathrm{m}^{2}$ in their $30 \mathrm{~s}$, which did not differ much from those of the National Nutrition Survey 2003 in Japan $\left(20.7 \pm 3.1\right.$ and $21.4 \pm 3.6 \mathrm{~kg} / \mathrm{m}^{2}$, respectively).

According to the criteria of the Japan Society for the Study of Obesity, BMI was categorized into underweight $\left(\mathrm{BMI}<18.5 \mathrm{~kg} / \mathrm{m}^{2}\right), \quad$ normal weight $\quad(18.5 \leq \mathrm{BMI}<$ $25 \mathrm{~kg} / \mathrm{m}^{2}$ ), and obesity (BMI $\geq 25 \mathrm{~kg} / \mathrm{m}^{2}$ ). In addition, in the International Statistical Classification of Diseases and Related Health Problems, Tenth Revision (ICD-10), BMI of $17.5 \mathrm{~kg} / \mathrm{m}^{2}$ or less is one of the criteria for anorexia nervosa [16]. Therefore, in our study, underweight was further classified into slightly underweight $(17.5<$ BMI $<18.5 \mathrm{~kg} / \mathrm{m}^{2}$ ) and severely underweight $(\mathrm{BMI} \leq$ $17.5 \mathrm{~kg} / \mathrm{m}^{2}$ ). A lymphocyte count of $<1,500 / \mathrm{mm}^{3}$ was defined as low based on nutritional assessment criteria [7].

A statistical analysis was made as follows: The linear trend, Student's $t$ test, Fisher's exact probability test, and chi-square test for trend were used to analyze the statistical differences in physical data among BMI groups and between the food-intake-restricting and nonrestricting groups. The association of low lymphocyte count with being underweight and restricting food intake was investigated with a logistic regression analysis after adjusting for age. $P$ values of $<0.05$ were considered statistically significant, and $P$ values from 0.05 to 0.10 were regarded as borderline significant. All statistical analyses were completed with the statistical package SPSS 14.0 J for Windows.

\section{Results}

As shown in Table 1, subjects were classified as ten (8.8\%) severely underweight, 13 (11.4\%) slightly underweight, 81 $(71.1 \%)$ normal weight, and ten $(8.8 \%)$ obese. The prevalence of underweight subjects (BMI $<18.5 \mathrm{~kg} / \mathrm{m}^{2}$ ) was $20.2 \%$ in total. There was no difference in age among the BMI groups. Among blood examinations, lymphocyte count tended to be lower with a decrease in BMI (trend $P=0.058$ ). Leukocyte count, neutrophil count, and total serum protein did not differ among BMI groups.

Table 1 Characteristics according to body mass index (BMI) groups

\begin{tabular}{llllll}
\hline & $\begin{array}{l}\text { Severely underweight } \\
(n=10)\end{array}$ & $\begin{array}{l}\text { Slightly underweight } \\
(n=13)\end{array}$ & $\begin{array}{l}\text { Normal } \\
(n=81)\end{array}$ & $\begin{array}{l}\text { Obese } \\
(n=10)\end{array}$ \\
\hline Total protein $(\mathrm{g} / \mathrm{dl})$ & $7.67 \pm 0.16$ & $7.56 \pm 0.28$ & $7.48 \pm 0.35$ & $7.52 \pm 0.33$ & 0.144 \\
Leukocyte $\left(\times 10^{3} / \mathrm{mm}^{3}\right)$ & $5.71 \pm 1.48$ & $5.69 \pm 1.39$ & $5.72 \pm 1.36$ & $6.44 \pm 1.29$ & 0.384 \\
Neutrophil $\left(\times 10^{3} / \mathrm{mm}^{3}\right)$ & $3.63 \pm 1.09$ & $3.46 \pm 0.95$ & $3.40 \pm 0.92$ & $3.73 \pm 0.67$ & 0.904 \\
Lymphocyte $\left(\times 10^{3} / \mathrm{mm}^{3}\right)$ & $1.68 \pm 0.54$ & $1.75 \pm 0.43$ & $1.85 \pm 0.46$ & $2.07 \pm 0.34$ & 0.058 \\
BMI $\left(\mathrm{kg} / \mathrm{m}^{2}\right)$ & $16.6 \pm 0.63$ & $18.0 \pm 0.29$ & $20.7 \pm 1.55$ & $27.2 \pm 2.57$ & - \\
\hline
\end{tabular}

Severely underweight $\left(\mathrm{BMI} \leq 17.5 \mathrm{~kg} / \mathrm{m}^{2}\right)$, slightly underweight $\left(17.5<\mathrm{BMI}<18.5 \mathrm{~kg} / \mathrm{m}^{2}\right)$, normal $\left(18.5 \leq \mathrm{BMI}<25 \mathrm{~kg} / \mathrm{m}^{2}\right)$, obese $\left(\mathrm{BMI} \geq 25 \mathrm{~kg} / \mathrm{m}^{2}\right)$

Data are expressed as mean \pm standard deviation

* By linear trend 
Comparing the two groups according to restricted food intake, BMI was higher in the restricting subjects $(P=0.050)$, as obese subjects were more likely to restrict food intake for weight loss (Table 2). Total serum protein, leukocyte count, and lymphocyte count were significantly lower in restricting subjects $(P<0.05)$.

The prevalence of low lymphocyte count of $<1,500 /$ $\mathrm{mm}^{3}$ increased with being underweight (trend $P=0.049$ ); the prevalence was $40 \%$ in the severely underweight group (Table 3). A multivariate logistic regression analysis showed an association of low lymphocyte count to severely underweight [odds ratio (OR): $1.95 ; 95 \%$ confidence interval (CI): 1.07-3.56] and restricted food intake for weight loss (OR: 3.73; 95\% CI: 0.91-15.30).

In seven women of normal weight who were restricting food intake, lymphocyte count showed a low value of $1,477.9 \pm 221.1 / \mathrm{mm}^{3}$, and a low lymphocyte count of $<1,500 / \mathrm{mm}^{3}$ was found in three $(42.9 \%)$ of them. One underweight subject who had restricted food intake had a very low lymphocyte count of $928 / \mathrm{mm}^{3}$.

\section{Discussion}

This study suggests that underweight Japanese women in their 20s and 30s may be in a state of subclinical malnutrition, as represented by low lymphocyte count. In severely underweight women with BMI of $\leq 17.5 \mathrm{~kg} / \mathrm{m}^{2}$, low lymphocyte count of $<1,500 / \mathrm{mm}^{3}$ was encountered in $40 \%$ and was also found in $43 \%$ of food-intake-restricting women of normal weight. This multivariate logistic regression analysis suggests that severely underweight women with a BMI $\leq 17.5 \mathrm{~kg} / \mathrm{m}^{2}$ and women who restrict food intake for weight loss may have a higher risk for low lymphocyte count.

Lymphocyte count and albumin levels are used as indicators of malnutrition $[8,9]$. In malnutrition, lymphocyte count tends to be reduced [7]. Lymphocyte count is correlated with the nutritional assessment scale [17]. An earlier study reported a decline in leukocyte, erythrocyte, and platelet counts in patients with anorexia nervosa who were severely thin [3]. Malnutrition may suppress hematopoiesis and particularly lymphocyte count. It is hence considered that low lymphocyte count is indirectly associated with malnutrition in severely underweight women and persons who are restricting food intake for weight loss.

Underweight subjects are supposed to tend to eat little, which can lead to lower protein intake. In our study, the low lymphocyte count was found particularly in severely underweight women. Earlier studies reported a decreased lymphocyte count in patients with anorexia nervosa who were severely underweight $[11,18]$. In our study, being
Table 2 Characteristics according to restricted food intake mean \pm standard deviation

* By Student's $t$-test

\begin{tabular}{llll}
\hline & Restricting $(n=10)$ & Not restricting $(n=104)$ & $P$ value* \\
\hline Total protein $(\mathrm{g} / \mathrm{dl})$ & $7.21 \pm 0.38$ & $7.54 \pm 0.32$ & 0.002 \\
Leukocyte $\left(\times 10^{3} / \mathrm{mm}^{3}\right)$ & $4.95 \pm 1.17$ & $5.86 \pm 1.36$ & 0.044 \\
Neutrophil $\left(\times 10^{3} / \mathrm{mm}^{3}\right)$ & $2.95 \pm 0.68$ & $3.50 \pm 0.92$ & 0.066 \\
Lymphocyte $\left(\times 10^{3} / \mathrm{mm}^{3}\right)$ & $1.54 \pm 0.38$ & $1.87 \pm 0.46$ & 0.030 \\
BMI $\left(\mathrm{kg} / \mathrm{m}^{2}\right)$ & $22.3 \pm 4.84$ & $20.5 \pm 2.61$ & 0.050 \\
\hline
\end{tabular}

Table 3 Association of low lymphocyte count $\left(<1,500 / \mathrm{mm}^{3}\right)$ with being underweight and restricting food intake

\begin{tabular}{|c|c|c|c|c|c|}
\hline & \multicolumn{2}{|l|}{ Lymphocyte count } & \multirow[t]{2}{*}{$P$ value* } & \multirow[t]{2}{*}{ Multivariate $\mathrm{OR}^{\mathrm{a}}(95 \% \mathrm{CI})$} & \multirow[t]{2}{*}{$P$ value } \\
\hline & Normal $\left(\geq 1,500 / \mathrm{mm}^{3}\right)$ & Low $\left(<1,500 / \mathrm{mm}^{3}\right)$ & & & \\
\hline \multicolumn{6}{|c|}{ Body mass index (BMI) groups } \\
\hline Severely underweight & $6(60.0)$ & $4(40.0)$ & 0.049 & $1.95(1.07-3.56)$ & 0.030 \\
\hline Slightly underweight & $10(76.9)$ & $3(23.1)$ & & & \\
\hline Normal & $64(79.0)$ & $17(21.0)$ & & & \\
\hline Obese & $10(100.0)$ & $0(0.0)$ & & & \\
\hline \multicolumn{6}{|c|}{ Restricted food intake group } \\
\hline Restricting & $6(60.0)$ & $4(40.0)$ & 0.213 & $3.73(0.91-15.30)$ & 0.067 \\
\hline Not restricting & $84(80.8)$ & $20(19.2)$ & & & \\
\hline
\end{tabular}


severely underweight was defined as BMI of $\leq 17.5 \mathrm{~kg} / \mathrm{m}^{2}$, which is one of the criteria of anorexia nervosa according to the ICD-10. Our subjects were healthy and did not have anorexia nervosa. Nevertheless, $40 \%$ of severely underweight women had a low lymphocyte count of $<1,500 /$ $\mathrm{mm}^{3}$. Being underweight at $\leq 17.5 \mathrm{~kg} / \mathrm{m}^{2}$ carries a high risk of low lymphocyte count.

Restricted food intake for weight loss can lead to malnutrition. In this study, total serum protein and lymphocyte count were lower in women who had restricted food intake, although BMI was greater in those women. A multivariate logistic regression analysis showed the association of low lymphocyte count with restricted food intake for weight loss (OR: 3.73; 95\% CI: 0.91-15.30) and with being underweight (OR: 1.95 ; 95\% CI: 1.07-3.56), showing that restricted food intake as well as being underweight may carry a higher risk of a low lymphocyte count. In particular, a low lymphocyte count was found in $43 \%$ of women of normal weight with restricted food intake. One underweight woman who had restricted food intake had an extremely low lymphocyte count of $928 / \mathrm{mm}^{3}$. Restriction of food intake for weight loss in normal or underweight persons appears to increase the risk of low lymphocyte count.

This study suggests that being severely underweight and restricting food intake for weight loss in adult women can be risk factors of low lymphocyte count, an indicator of malnutrition. It is important for young women to maintain a BMI of $>17.5 \mathrm{~kg} / \mathrm{m}^{2}$ and not to restrict food intake if of normal body weight or if underweight to prevent malnutrition.

In this study, total serum protein was not different among BMI groups. Various kinds of protein, such as albumin, globulin, and the like make up total protein, which is expected to be less sensitive to protein malnutrition. Serum albumin is generally used as an indicator of protein nutritional status. It is also reported that lymphocyte count may reflect a status of shorter-term protein nutrition [19]. Hence, a low lymphocyte count in underweight persons may reflect an acute but not chronic state of lower protein intake, which may be represented by albumin levels, which was not examined in this study. More detailed studies are necessary on protein malnutrition in underweight subjects.

Our study has some limitations, as it was conducted only on 114 Japanese women, among whom ten were severely underweight. Moreover, we did not examine serum albumin levels as an indicator of protein malnutrition, nor were detailed food intake contents examined. Therefore, further studies are warranted to obtain more conclusive results.

Acknowledgments This study was supported by a research grant from the Nagoya Public Health Institute.

\section{References}

1. Osako M, Takayama T, Kira S. Dietary habits, attitudes toward weight control, and subjective symptoms of fatigue in young women in Japan. Nippon Koshu Eisei Zasshi. 2005;52:387-98. (Article in Japanese, English abstract).

2. Takimoto H, Yoshiike N, Kaneda F, Yoshita K. Thinness among young Japanese women. Am J Public Health. 2004;94:1592-5.

3. Kiriike N, Nagata T, Nakanishi S, Okuno M, Matsunaga H, Katayama M, et al. Blood biochemical abnormalities of patients with anorexia nervosa and bulimia. Jap J Clin Psychiatry. 1990;19:609-16. (Article in Japanese).

4. Rico H, Arribas I, Casanova JF, Duce MA, Hernández RE, Cortes-Prieto J. Bone mass, bone metabolism, gonadal status and body mass index. Osteoporos Int. 2002;13:379-87.

5. Copeland PM, Sacks NR, Herzog DB. Longitudinal follow-up of amenorrhea in eating disorders. Psychosom Med. 1995;57:121.

6. van Hooff MH, Voorhorst FJ, Kaptein MB, Hirasing RA, Koppenaal C, Schoemaker J. Relationship of the menstrual cycle pattern in 14-17 year old old adolescents with gynaecological age, body mass index and historical parameters. Hum Reprod. 1998;13:2252-60.

7. Omran LM, Morley EJ. Assessment of protein energy malnutrition in old persons. Part II: laboratory evaluation. Nutrition. 2000;16:131-40.

8. Dzieniszewski J, Jarosz M, Szczygiel B, Dlugosz J, Marlicz K, Linke K, et al. Nutritional status of patients hospitalised in Poland. Eur J Clin Nutr. 2005;59:552-60.

9. Koval KJ, Maurer SG, Su ET, Aharonoff GB, Zuckerman JD. The effects of nutritional status on outcome after hip fracture. J Orthop Trauma. 1999;13:164-9.

10. Seltzer HM, Bastidas AJ, Cooper MD, Engler P, Slocum B, Fletcher SH. Instant nutritional assessment. JPEN J Parenter Enteral Nutr. 1979;3:157-9.

11. Nagata T, Kiriike N, Tobitani W, Kawarada Y, Matsunaga H, Yamagami S. Lymphocyte subset, lymphocyte proliferative response, and soluble interleukin-2 receptor in anorexic patients. Biol Psychiatry. 1999;45:471-4.

12. Nasu M, Fujiyasu S, Iwatani Y, Amino N, Tanizawa O, Miyai K. Changes of differential leukocyte counts during pregnancy and in the postpartum period. Rinsho Byori. 1992;40:1292-6.

13. Momose Y, Une H, Ikui H, Esaki H. The relationship between the white blood cell count and cigarette smoking among Japanese males. J Occup Health. 1997;39:280-4.

14. Parry H, Cohen S, Schlarb EJ, Tyrrell AJD, Fisher A, Russell AHM, et al. Smoking, alcohol consumption, and leukocyte counts. Am J Clin Pathol. 1997;107:64-7.

15. Sano J, Ono H, Aoki Y. Study of exclusion criteria for reference counts and leukocyte differential ratio: 1st report the effects of smoking, drinking, ageing. Igaku Kensa. 1998;47:1199-202. (Article in Japanese).

16. World Health Organization. The ICD-10 classification of mental and behavioral disorders: clinical descriptions and diagnostic guidelines. Geneva: World Health Organization; 1992.

17. Sungurtekin H, Sungurtekin U, Hanci V, Erdem E. Comparison of two nutrition assessment techniques in hospitalized patients. Nutrition. 2004;20:428-32.

18. Mustafa A, Ward A, Treasure J, Peakman M. T lymphocyte subpopulations in anorexia nervosa and refeeding. Clin Immunol Immunopathol. 1997;82:282-9.

19. Kasai H, Kobayashi N, Kosaka Y, Shimizu A. Effectiveness of serum rapid turnover protein evaluations by clinical pathway: studies on cases after percutaneous endoscopic gastrostomy. Igaku Kensa. 2006;55:725-31. (Article in Japanese, English abstract). 